\title{
Avaliação de contratos: uma abordagem utilizando a Análise Fatorial de Correspondência
}

\author{
Weimar Freire da Rocha Junior ${ }^{1}$ \\ Elizângela Mara Carvalheiro ${ }^{2}$ \\ Jefferson Andronio Staduto ${ }^{3}$ \\ Miguel Angel Uribe Opazo ${ }^{4}$
}

Resumo: Este trabalho, à luz da Nova Economia Institucional (NEI), avaliou nove contratos, destacando alguns usados no agronegócio brasileiro. Para isso, usaram-se os atributos da transação nos três principais vetores que os caracterizam, os quais possibilitam arquitetar formas contratuais que tenham o menor custo de transação. $\mathrm{O}$ fato de os contratos serem uma modalidade de estrutura de governança, quando considerados de forma ampla, representam os mais variados acordos entre os agentes econômicos. Neste sentido, a análise a ser desenvolvida utilizará um método estatístico multivariado que avaliará

\footnotetext{
${ }^{1}$ Professor Adjunto do Curso de Ciências Econômicas e do Programa de Mestrado em Desenvolvimento Regional e Agronegócio da UNIOESTE-Toledo. Membro do Grupo de Pesquisa em Agronegócio e Desenvolvimento Regional - GEPEC. E-mail: wrocha@ unioeste.br

${ }^{2}$ Doutoranda pelo Programa de Pós-graduação em Desenvolvimento Rural - UFRGS e membro do Grupo de Pesquisa em Agronegócio e Desenvolvimento Regional - GEPEC. Rua da Faculdade, 645. CEP: 85903-000. Toledo (PR-Brasil). E-mail: elizangelamara@ ibest.com.br

${ }^{3}$ Professor Adjunto do Curso de Ciências Econômicas e do Programa de Mestrado em Desenvolvimento Regional e Agronegócio da UNIOESTE-Toledo. Membro do Grupo de Pesquisa em Agronegócio e Desenvolvimento Regional - GEPEC. Pesquisador do CNPq. E-mail: staduto@unioeste.br

${ }^{4}$ Professor Associado do Centro de Ciências Exatas e Tecnológicas UNIOESTE-Cascavel e do Programa de Mestrado em Desenvolvimento Regional e Agronegócio da UNIOESTE-Toledo. Membro do Grupo de pesquisa de Geoestatística Aplicada. E-mail: mopazo@unioeste.br
} 
nove contratos, em sua maioria em consonância com o agronegócio: cinco contratos de venda, três contratos de franquia, um contrato de parceria agrícola. Essas relações possibilitaram enfatizar quais são as principais preocupações dos agentes quando firmam relações contratuais entre si, ou seja, qual ou quais atributos da transação está(ão) implícito(s) na elaboração dos contratos. Como resultado, observou-se que os contratos de compra e venda de cana-de-açúcar 2 e 3, compra e venda de mandioca, franquia de bebida/cachaça, franquia de produtos de concreto, franquia de escola de idiomas e parceria agrícola visam resguardar o atributo especificidade do ativo; e contratos de compra e venda de cana-de-açúcar 1, direciona para a freqüência. Já contratos de compra e venda de soja estão mais propensos à incerteza.

Palavras-chaves: Contrato, Economia dos custos de transação, Análise multivariada.

\section{Classificação JEL: Q13, L14}

Abstract: This study, in the light of transaction cost theory, has assessed the contractual relationships, eliciting the contracts in the Brazilian agribusiness. By using the transaction attributes in their main vectors of the features in which give the possibility to design the government structure of the lower cost. The contracts present a government structure, which when they are widely considered to represent a variety of agreement among the economic agents. On this system, the analysis to be developed is going to adopt a statistic multivariate method, which is going to assess nine contracts mostly consonant with the agribusiness (five contracts on sales, three on franchising and one on agriculture joint venture). These relationships facilitate to emphasize which are the main fears of the economic agents when they not only make contractual relationship among them but also what is/are the transaction attribute(s) implicit in the established contracts. As a result, it was also observed the purchase and sale contracts of sugar cane (two), franchising of beverages, concrete made products, language schools and agriculture joint venture which are more linked to the specific commodities. Purchase and sale contract of sugar cane (one), 
manioc and sugar cane (three) direct to a frequency. Purchase and sale contracts of soybean are inclined to be more uncertain.

Key words: Contract, transaction costs economy, multivariate analysis.

\section{JEL Classification: Q13, L14}

\section{Introdução}

O propósito deste trabalho é utilizar o referencial teórico da Nova Economia Institucional (NEI) para detectar a presença de especificidade do ativo, incerteza e freqüência (atributos da transação), implícitos nas relações contratuais, utilizando-se da técnica de análise de fatorial multivariada de correspondência.

Nos últimos anos, as transformações que estão ocorrendo na economia mundial, capitaneadas pelo processo de integração de mercados comerciais e financeiros, e pela difusão de um novo paradigma tecnológico, vêm modificando as estruturas produtivas, tanto em países desenvolvidos quanto em países cujas bases industriais ainda se encontram em processo de desenvolvimento.

Neste cenário de rápidas transformações, tornam-se relevantes, dentro dos estudos das organizações, as questões referentes à coordenação dos sistemas agroindustriais. Essa coordenação tem sido um tema muito debatido em razão da grande variedade de arranjos institucionais que têm surgido em diversas economias e sistemas. De acordo com Nogueira (2003), arranjos - como os contratos de fornecimento de longo prazo, sub-contratação (terceirização) de fornecedores de produtos e serviços, condomínios industriais, onde fornecedores operam nas instalações do próprio cliente, contratos de franquia, contratos de exclusividade de canal, entre outros - são estruturas de governança que vêm se estabelecendo com grande freqüência na atualidade. Ademais, as alterações que estão ocorrendo no ambiente institucional podem gerar novas questões relativas à defesa da concorrência para o setor público, desafios estratégicos para os agentes privados e temas de pesquisa para os acadêmicos que estudam as organizações. 
Com relação ao agronegócio, a análise da coordenação de sistemas agroindustriais se faz necessária em virtude das tendências, verificadas nas últimas décadas, de estreitamento dos relacionamentos e negociações entre as mais diversas etapas de transformação e consumo. Isto porque se passaram a ser consideradas as crescentes demandas por qualidade, variedade e segurança dos alimentos e seu fornecimento, entre os vários agentes participantes do sistema agroindustrial até os mercados consumidores domésticos e/ou internacionais. Por isso, os sistemas produtivos devem apresentar atualização tecnológica, padronização e uniformidade de oferta em qualquer nível de processamento industrial envolvido. De modo geral, um dos principais desafios encontrados nesse processo é conciliar a coordenação dos sistemas e as variáveis que influenciam todo o sistema, sem contar com as peculiaridades do agronegócio em seus aspectos intrínsecos de sazonalidade e perecibilidade da produção agropecuária dentre outros.

De acordo com Farina et al. (1997), a coordenação, ao longo de sistemas agroindustriais, utiliza-se de vários mecanismos de estrutura de governança, incluindo mercados (preços), contratos implícitos e alianças, contratos formais, joint-ventures e integração vertical. Neste sentido, pressupõe-se a existência de uma competição entre essas formas organizacionais alternativas, de forma que prevalecerá aquela que melhor atinja seu objetivo (redução de custos de transformação ${ }^{5}$, compartilhamento de riscos, poder de mercado) a um custo mais baixo, obtido pela redução de desperdício (first-order economizing).

Sob essa ótica, o sistema agroindustrial deixa de ser tratado como uma série de transposições de relações tecnológicas e passa a ser abordado como um nexo de contratos, proposto por Coase (1993) com as seguintes proposições: a) uma cadeia de suprimento pode ser encarada como um nexo de contratos ampliado, cuja arquitetura resulta de seu alinhamento com as características das transações e o ambiente institucional; b) existem arranjos contratuais que reproduzem a arquitetura contratual existente na firma, a motivação para a elaboração de um subsistema por algum agente dentro da cadeia parte das estratégias de mercado e a busca de

${ }^{5}$ Custos de transformação são os somatórios dos custos de produção e custos de transação. 
eficiência em custos de transação, podendo gerar contratos informais (ZYLBERSZTAJN, 1995).

De acordo com Zylbersztajn (2005), a complexidade, tanto quantitativa como qualitativa, das atividades gerenciais dos agentes participantes dos sistemas agroindustriais ocasiona condições de estabelecerem relações contratuais formais ou não entre estes agentes. Estas relações contribuem para o desenvolvimento de um ambiente fértil e estimulante à compreensão de formas contratuais, as quais, por serem tão óbvias, acabam sendo negligenciadas, mesmo que elas propiciem as mais variadas transações no agronegócio, do acesso à terra, aos contratos de créditos e de trabalho, além de contratos de financiamento de máquinas e equipamentos etc. Assim, considerando-se os argumentos aludidos pelos autores, o sistema agroindustrial pode apresentar um fluxo de informações e de relações que opera com grande grau de liberdade, ou mesmo autonomia em relação ao mercado, ou um subsistema estritamente coordenado, se um grau suficiente de controle puder ser aplicado. Além disso, diversos mecanismos de motivação e controle podem ser implementados para dar suporte à idéia de gestão de um sistema agroindustrial, como é o caso dos contratos firmados, sendo eles formais ou não. Zylbersztajn (2005) afirma que o uso de contratos eleva o valor da organização, melhora a eficiência e gera incentivo para sua utilização.

Diante deste contexto, é mister aprofundar os estudos comparados de formatações contratuais, os quais podem revelar, não somente particularidades dos mesmos e sua governança, mas, sobretudo, podem expor as diferenças que contribuem para aperfeiçoar a coordenação dos sistemas, bem como podem explorar os aspectos das relações existentes entre os contratos e a teoria dos custos de transação, destacando a presença dos atributos da transação: a incerteza, a especificidade do ativo e a freqüência.

\section{A teoria dos custos de transação}

O embasamento teórico Teoria dos Custos de Transação (TCT) aparece na obra de Ronald Coase, com a publicação do trabalho The Nature of the Firm, o qual investigou a razão da existência das firmas. Ele concluiu que a presença de custos de transação, mediante 
a utilização do sistema de preços, acarretava a coordenação de uma série de operações por parte das firmas e não pelo mercado, conforme defendia a teoria microeconômica tradicional. De acordo com o autor, certos tipos de transação, quando realizados pelo mercado, ocasionavam custos bastante elevados. O mecanismo de preço seria custoso não só para obter as informações corretas (os preços relevantes), mas também no que se refere ao tempo para a obtenção dessas informações. Assim, realizar a precificação de cada transação, com a formulação paralela de um contrato individual para cada uma delas, tornava-se extremamente penoso para as partes envolvidas numa negociação (FARINA et al., 1997).

O papel da firma, portanto, estaria justamente na redução desses custos, uma vez que ela permitiria a substituição de uma série de contratos de curto prazo por apenas um, de prazo mais longo, que seria suficientemente geral a fim de permitir a adaptação das partes envolvidas em função de contingências futuras (ZYLBERZTAJN; NEVES, 2000).

Nas décadas de 1970 e 1980, especialmente, a partir dos trabalhos realizados por Williamson (1975, 1980, 1996), a questão dos custos de transação ganha mais força dentro da literatura econômica. As contribuições desse autor foram de grande valia para a consolidação da Teoria dos Custos de Transação no debate acadêmico formal, e muitas de suas idéias ganharam contornos interdisciplinares, especialmente no que se refere à questão dos contratos. Estes eram compreendidos como mecanismos necessários à superação dos custos elevados, impostos pelo sistema de preços para a efetivação de uma transação.

Houve, porém, evolução no conceito dos custos de transação, os quais podem ser definidos em quatro níveis: o primeiro nível relaciona-se com os custos de construção e negociação dos contratos; o segundo envolve os custos por medir e monitorar os direitos de propriedade existentes no contrato. Esse nível incorpora os custos de observação dos contratos ao longo do tempo para seu desempenho e atende às expectativas das partes que fizeram a transação. O terceiro nível engloba os custos de manter e fazer executar os contratos internos e externos da firma. E o último nível relaciona-se aos custos de adaptação que os agentes sofrem com as mudanças ambientais (FARINA, 1999). 
Sendo o objetivo das instituições econômicas minimizar os custos de transação, os contratos seriam formas alternativas de alcançar esse objetivo.

Mas como as transações diferem umas das outras? Segundo Williamson (1981), a teoria da Economia dos Custos de Transação (ECT) afirma que a diversidade de estruturas de governaça é explicada, sobretudo, pelas diferenças básicas nos atributos das transações. Conjuntamente, explicam-se as questões da incerteza, da freqüência e da especificidade de ativos, as quais representam os três principais vetores capazes de caracterizar uma transação e de possibilitar o desenho de uma determinada estrutura de governança, com o objetivo de atenuar os custos de transação associados a essa mesma transação.

A freqüência é caracterizada pelo número de vezes que é realizada uma determinada transação entre dois agentes. Nesta, a transação poderá ser ocasional (agentes não desenvolvem qualquer tipo de relacionamento) ou recorrente (os agentes têm interesse em permanecer na transação porque se criam dependências entre eles e pelo que se ganha em aprendizado). Presume-se que as formas de contrato entre os agentes sejam diferentes e tenham o intuito de evitar uma crise futura que possa gerar uma perda de renda por uma das partes, em função do rompimento do contrato. Pode-se afirmar que uma determinada espécie de transação pode apresentar diferentes níveis de freqüência. Conforme apresenta FARINA et al. (1997, p. 88), “a importância desta dimensão manifesta-se em dois aspectos: a) a diluição dos custos de adoção de um mecanismo complexo por várias transações e, b) a possibilidade de construção de reputação por parte dos agentes envolvidos na transação”.

A incerteza, por sua vez, vincula-se diretamente às hipóteses comportamentais - racionalidade limitada e oportunismo - que dificultam previsões consistentes de eventos futuros. Há incerteza quanto ao reconhecimento das informações relevantes ao contrato ou, mais precisamente, essas informações são incompletas e assimétricas. Dessa forma, as incertezas provenientes do mercado não permitem que os agentes criem cláusulas contratuais que associem os resultados futuros do contrato com a realidade futura do mercado.

A especificidade de ativos está diretamente relacionada com a possibilidade de reemprego ou utilização alternativa de um ativo sem 
que este tenha perda de valor. Ativos altamente específicos, portanto, teriam sua utilização bastante restrita. Assim, agentes envolvidos em transações caracterizadas pela presença de ativos idiossincráticos teriam maior interesse em dar continuidade à relação, uma vez que o grau de especificidade do ativo poderia tornar tal relacionamento um monopólio bilateral. A maior especificidade de um ativo traria implicações sobre a formatação do contrato a ser firmado, uma vez que um maior número de salvaguardas seria exigido. Ativos de baixa especificidade, por outro lado, seriam facilmente reempregados, dispensando arranjos contratuais mais complexos (ZYLBERSZTAJN, 1995; FARINA, 1999).

Diante desta contextualização, o estudo dos contratos tem sido uma vertente essencial ao longo da evolução da Economia do Custo de Transação (ECT), em razão do reconhecimento de sua função, como a de governar as transações. Considerados de forma ampla, eles representam os mais variados acordos entre os agentes, podendo aparecer entre firmas no mercado, como uma simples transação de compra e venda, dentro das firmas, como um contrato de trabalho, ou extra firma, como um contrato de prestação de serviços.

Zylbersztajn (1995) destaca o estudo das relações contratuais como uma das principais áreas da Nova Economia Institucional, da qual a ECT faz parte, e que envolve outras áreas, como Economia, Direito e Administração, ainda que estas tenham enfoques diferentes sobre os contratos. A Economia considera os aspectos ligados à eficiência, enquanto que para o Direito o critério de avaliação dos contratos seria a justiça.

A lei faz valer o contrato e as Ciências Econômicas complementam e auxiliam no esboço e escolha do contrato. O conceito econômico do contrato tem como sua essência a promessa; isso possibilita aos agentes econômicos a realização de investimentos e negócios, tendo-o como um elemento de garantia e salvaguarda contra risco futuro de ruptura da promessa (SZTAJN, ZYLBERSZTAJN, AZEVEDO, 2005).

Assim, a forma de estruturação de um contrato vai depender das características dos agentes presentes, em que poderão estar presentes o oportunismo (comportamento aético que resulta em custos para os agentes que estão transacionando - beneficiar a si próprio) e a racionalidade limitada (os agentes são incapazes de estipular todas as 
contingências de um contrato previamente estipulado) (NORTH, 1994). No entanto, de acordo com NOGUEIRA (2003), deve-se considerar os seguintes aspectos dos contratos:

Incompletude: característica fundamental de qualquer contrato, deriva da impossibilidade de se prever eventos ou comportamentos futuros, assim como da racionalidade limitada dos agentes que seriam incapazes de considerar todos os aspectos relevantes das transações envolvidas. O desenvolvimento de uma teoria dos contratos deve, portanto, contemplar regras para o preenchimento das lacunas inevitáveis dos contratos.

Custos: são relativos à negociação, elaboração, monitoramento, criação e aplicação de mecanismos para a solução de conflitos e para a punição de comportamentos indesejados. Uma das formas encontradas pela sociedade para reduzir os custos na solução de conflitos foi a criação de instituições estruturadas para esse fim, como tribunais formais ou informais. A firma pode ser considerada uma estrutura apta a resolver uma parcela significativa das disputas, por meio da hierarquia.

Duração: concebidos, em geral, com prazo indeterminado, os contratos podem ser temporários a priori ou ter a duração interrompida por quebras contratuais unilaterais ou novas etapas de negociação. A presença de ativos específicos gera a necessidade de compromissos com prazos mais longos, suficientes para que se recupere o investimento realizado.

Williamson $(1979 ; 1981)$ oferece uma análise detalhada de três arranjos contratuais básicos, cada um representando uma estrutura de governança. Ele considera cada contrato como uma função de p (preços), k (especificidade de ativos) e s (salvaguardas).

Nos contratos clássicos, característicos das relações de mercado, o preço é determinante, enquanto k e s são baixos, se não nulos. São os contratos básicos da economia, em que a identidade das partes torna-se irrelevante. O mercado, ou alguma outra instituição organizada, estaria encarregado de criar um bem homogêneo que garantisse a realização da transação sem que as partes envolvidas tivessem que ser identificadas. Ademais, a natureza do acordo é delimitada e há um grande incentivo à descrição. Por fim, observa-se, nesse tipo de contrato, a predominância de contornos formais e um claro desincentivo à participação de 
terceiros na resolução de conflitos (litígio em vez de arbitragem).

Contratos neoclássicos: característicos das formas híbridas, os preços têm um papel importante no ajustamento, que é limitado pela presença de ativos específicos (k é positivo); e as salvaguardas são de difícil implementação. São contratos de longo prazo executados normalmente em um ambiente de incerteza. Aqui, diferentemente do contrato clássico, a identidade das partes é relevante, e, devido aos incentivos à continuidade da relação, temos uma substituição do litígio pela arbitragem. O prolongamento da relação é função da existência de ativos específicos que criam uma espécie de lock in entre os agentes envolvidos e suscitam a estruturação de formas contratuais mais flexíveis, que prevejam adaptações a fim de evitar a perda dos investimentos realizados. Os contratos, nesse sentido, apresentam algumas lacunas (contratos incompletos), cujo preenchimento se dá no decorrer das negociações.

Há também os contratos relacionais: caracterizados como uma alternativa contratual quando a duração e a complexidade das relações são elevadas. Ao contrário do contexto neoclássico, que tem como referência o contrato original, esse contrato não utiliza essa referência, mas a inteira relação com a forma que vai se desenrolando ao longo do tempo. As transações, que são caracterizadas por esse tipo de contrato, são de muito longo prazo. Os contratos relacionais seriam, segundo Williamson, uma espécie de pequena sociedade repleta de normas balizadoras.

Conforme apresenta Macedo Jr. (1998), com a globalização, os contratos passam a ter uma dimensão cada vez mais relacional, uma vez que a necessidade de produtos competitivos exige permanente inovação por meio da produção de uma especialização flexível, em que são necessárias contínuas transações entre vendedores e compradores.

Alguns fatores podem levar os agentes a não quebrarem os contratos, entre os quais citam-se: a reputação (em que o agente preserva o contrato, pois tem conhecimento de que tal ação irá interromper o fluxo de renda futura e que o custo do rompimento supera os benefícios de lucros futuros); as garantias legais (a existência de mecanismos punitivos criados pela sociedade faz com que os agentes se desestimulem para a quebra de contrato oportunista, pois este dispositivo pode estar em forma de cláusula no contrato, como por exemplo multa por atraso de 
cumprimento das datas do contrato); e os princípios éticos - uma espécie de código de conduta dos agentes - (ZYLBERSZTAJN; NEVES, 2000).

Se, por um lado, existe a possibilidade de não haver quebras e querelas contratuais, por outro, o conflito poderá vir a ser iminente, por isso há a necessidade de contratos que resguardem determinadas especificidades entre, por exemplo, o agente e o principal. A assimetria de informação pode gerar essas querelas entre esses indivíduos. Ex-ante, o contratante é, em geral, o único que possui informações privilegiadas. Portanto, encontra-se em melhor posição para avaliar o valor econômico e negociar. Ex-post, é o contratado que adquirirá informações mais completas sobre a sua área de exploração. Nem sempre o esquema de produção apresentado pelo "agente" converge totalmente com os interesses do "principal". Por outro lado, tanto os "agentes" como o "principal” tentam capturar a maior parte possível da renda gerada no negócio. O Contrato, portanto, visa amenizar o conflito complexo de "partilha de rendas sob grande assimetria de informações” (AZEVEDO, 1996).

Em vista disso, os contratos das empresas com produtores tendem a apresentar: mecanismos de monitoramento e definição de preços mais transparentes e facilmente verificáveis: verificação ou arbitragem por terceiros; direitos e responsabilidades mais detalhados sobre um universo maior de contingências; mais direitos de decisão dos contratantes sobre as atividades dos produtores e pagamentos de valores menos correlacionados diretamente com os lucros da contratante aos produtores.

Com essa caracterização, torna-se necessário destacar quais são os fatores que influenciam nas relações contratuais entre os agentes. Para tanto, será utilizada a Análise Fatorial de Correspondência (AFC), a qual possibilita o cruzamento de dados dos contratos das empresas com os atributos da transação (características qualitativas e/ou quantitativas).

\section{Análise metodológica}

A análise realizada neste estudo pode ser considerada tanto: descritiva, em que o objetivo primordial é a descrição das características de determinada população ou fenômeno ou, ainda, o estabelecimento de relações entre variáveis (GIL, 2000); como explicativa, pois vai além da simples 
identificação da existência de relações entre as variáveis, pretendendo discutir a natureza dessa relação, ou seja, quais são as influências que a teoria dos custos de transação exercem sobre a formulação e elaboração de um contrato. Dessa forma, em função do caráter descritivo (aproximando-se do explicativo), e à guisa de uma revisão bibliográfica acerca da Economia dos custos de transação e análise de correspondência, são analisados elementos considerados importantes para a caracterização da importância da especificidade do ativo, incerteza e freqüência (atributos básicos da Teoria da Economia dos Custos de Transação) na explicação da diversidade contratual.

A análise desenvolvida considerou uma amostra de nove contratos de segmentos diferenciados (cinco contratos de venda e compra de: cana-de-açúcar, mandioca e soja; três contratos de franquia; e um contrato de parceria agrícola). O embasamento teórico foi feito a partir de uma revisão de literatura sobre os principais conceitos e/ou aplicações da estatística análise fatorial de correspondência (AFC), em que foram revisitados autores como: Benzécri et al. (1973); Carrol et al. (1986); Hoffman e Franke (1986); Carrol e Green (1988); Carrol et al. (1989); Greenacre (1989); e Kaciak e Louviere (1990).

A análise fatorial de correspondência é uma técnica de análise multivariada, que se baseia na obtenção de fatores e escores por meio de variâncias e covariâncias (MARDIA; KENT, BIBBY, 1989). A AFC é uma técnica de análise exploratória utilizada para estudar as associações entre duas ou mais variáveis categóricas, permitindo a visualização das relações entre linhas e colunas num mesmo espaço gráfico (SILVA; VERDINELLI, 1997). Por meio da AFC, procura-se encontrar as relações recíprocas, associações e oposições, entre variáveis ou entre objetos e variáveis (BENZÉCRI et al., 1973). Com a AFC, pode-se estudar as tabelas de freqüência cruzada, conhecidas como tabelas de contingência, as matrizes onde as linhas representam objetos ou indivíduos e as colunas variáveis, com uma ou várias modalidades.

Existe uma grande semelhança entre a análise fatorial de correspondência e a análise de componentes principais, que é o método fatorial mais comum. No entanto, uma das diferenças é que, na análise de componentes principais, os dados são quantitativos, enquanto que na AFC são qualitativos ou quantitativos codificados, ou dados contínuos 
discretizados, com a restrição de que sejam positivos (VERDINELLI, 1980). Como nos outros métodos fatoriais, na AFC pode-se reduzir o espaço de representação sem perdas substanciais de informação.

A análise fatorial de correspondência, essencialmente, é um algoritmo que, por manipulações algébricas, a partir de uma tabela de contingência, permite uma visão simplificada da realidade multidimensional. Possui como referência a hipótese de interdependência entre as variáveis. Pode-se, também, considerar essa análise altamente flexível com os dados requisitados (HOFFMAN; FRANKE, 1986).

De fato, trabalha-se com conjuntos de variáveis categóricas com grande número de modalidades que possuem inter-relações difíceis de serem entendidas. A utilização da AFC torna possível a interpretação das variáveis sob as representações geométricas, revelando a estrutura dos dados de forma ótima, sem necessidade de assumir modelos ou distribuições conhecidas. Nesse contexto, a AFC é uma técnica de análise exploratória de dados que possibilita gerar hipóteses a partir das associações e oposições estudadas.

Neste sentido, Nogueira (2003) relata que a AFC é um método que consiste em duas etapas básicas. Na primeira é efetuado o cálculo da medida de associação por meio da distribuição da estatística do quiquadrado para padronizar os valores das freqüências e formar a base para as associações. A partir de uma tabela de contingência, calculam-se as freqüências esperadas e o valor de qui-quadrado para cada célula, considerando-se as diferenças entre as freqüências observadas e as esperadas ao quadrado. A padronização é necessária porque é mais fácil a ocorrência de diferenças em células com altas freqüências do que naquelas com valores pequenos.

Na segunda etapa é criado um mapa perceptual, os valores de similaridade (qui-quadrado) oferecem uma medida padronizada da associação. Com essas medidas, a análise de correspondência cria uma medida em distância métrica e cria dimensões ortogonais sobre as quais as categorias podem ser projetadas, de forma a representar o grau de associação dado pelas distancias do valor qui-quadrado (NOGUEIRA, 2003).

Tecnicamente, os planos fatoriais ou inerciais de representação (subespaços vetoriais) permitem mostrar os relacionamentos entre linhas e colunas da tabela (em nosso caso, contratos e atributos da 
transação). As linhas e colunas são representadas por um ponto determinado pelo vetor de freqüências de suas células - num espaço euclidiano, e as distâncias entre os pontos, ou entre esses e o centro de gravidade - a origem de coordenadas - são medidas em distâncias de $\chi^{2}$ (qui-quadrado). A contribuição à inércia da nuvem dos pontos-variáveis relaciona-se com sua distância ao centro de coordenadas; assim, quanto mais distante do centro, maior a sua contribuição.

De acordo com Carroll et al. (1986), dada uma matriz de freqüência $\mathrm{F}$, que tem os perfis marginais linha e marginais coluna representados em duas matrizes diagonais $\mathrm{R}$ e $\mathrm{C}$, a primeira transformação ocorre na normalização da matriz $\mathrm{F}$, quando da geração de uma nova matriz $\mathrm{H}$, da seguinte forma:

$$
\mathrm{H}=\mathrm{R}^{-1 / 2} \mathrm{~F} \mathrm{C}^{-1 / 2}
$$

O segundo passo é encontrar o valor singular de decomposição da matriz $\mathrm{H}$, assim denotado:

$$
\mathrm{H}=\mathrm{P} \Delta \mathrm{Q}^{\prime}
$$

Em que P' $\mathrm{P}=\mathrm{Q}^{\prime}, \mathrm{Q}^{\mathrm{t}} \mathrm{Q}=\mathrm{I}$ e $\Delta$ é diagonal. Nesta transformação, o primeiro autovetor de solução trivial não é considerado.

O terceiro e último passo define a configuração das coordenadas linhas e colunas, respectivamente, X e Y, após reduzir as dimensões matriciais.

$$
\begin{aligned}
& \mathrm{X}=\mathrm{R}^{-1 / 2} \mathrm{P} \Delta \\
& \mathrm{Y}=\mathrm{C}^{-1 / 2} \mathrm{Q}
\end{aligned}
$$

Os conjuntos de coordenadas transformadas X e Y representam o conjunto de interesse em trabalhos que abordem a AFC e permitem a utilização de um mesmo espaço gráfico de linhas e colunas. Entretanto, cada conjunto deve ser analisado separadamente (HOFFMAN; FRANKE, 1986). A escala tradicional com as coordenadas X e Y não permite esse tipo de interpretação. 

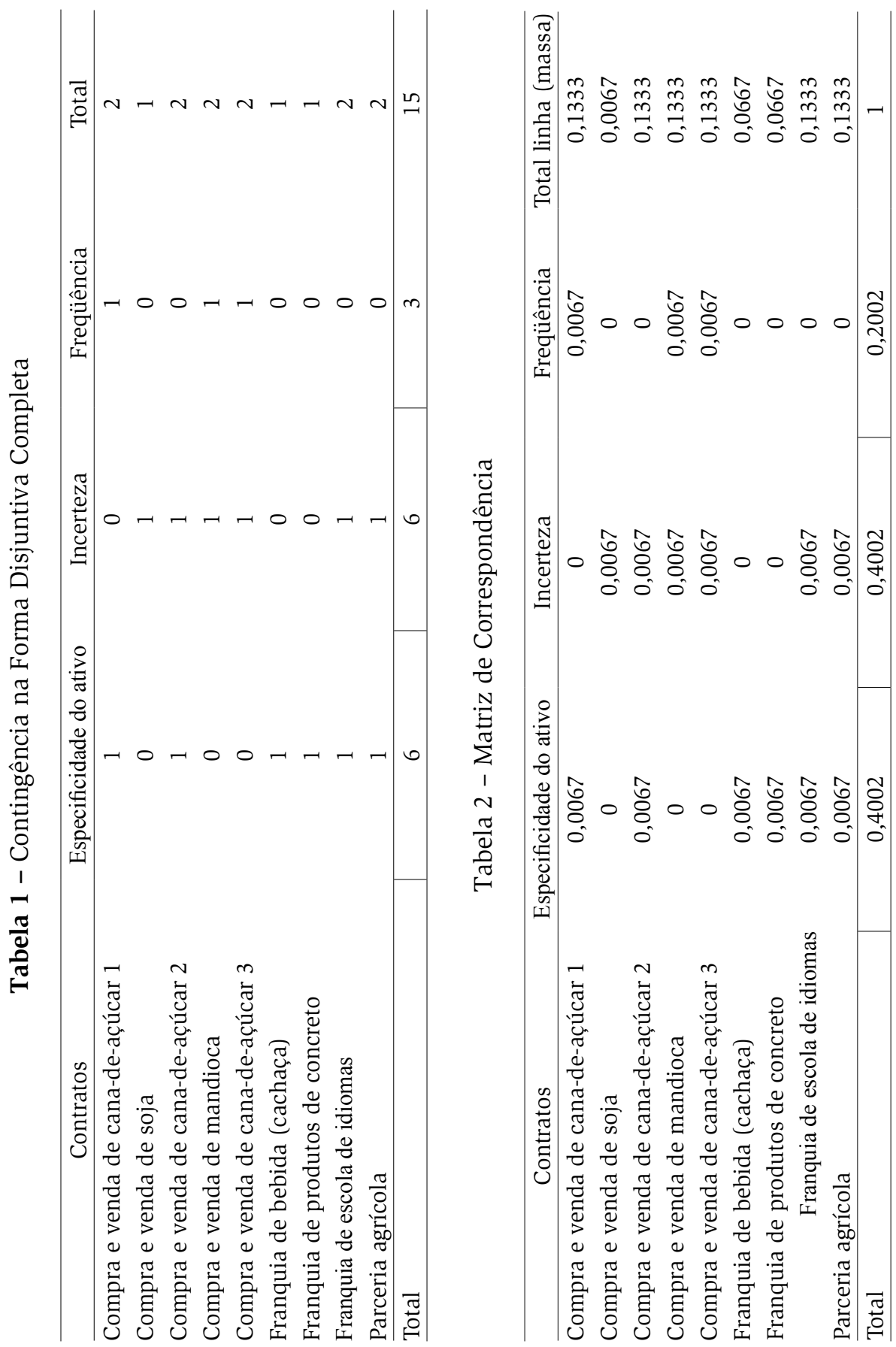
Primeiramente, constrói-se uma tabela de contingência na forma disjuntiva completa (em que estejam presentes os caracteres qualitativos e os contratos). O número de contratos analisado foi nove $(\mathrm{n}=9)$, os quais formam classificados de acordo os atributos da transação (especificidade do ativo, incerteza e freqüência). Para cada um dos nove contratos usados neste estudo, foi criada uma variável dicotômica 1 e 0 . A variável recebeu escore 1 se no contrato for detectada a presença de algum dos atributos da transação e escore 0 se não fosse detectado a presença (Tabela 1) e a matriz de correspondência (Tabela 2).

\section{Resultados e discussões}

Devido às necessidades específicas, seja na área tecnológica (P\&D Pesquisa e Desenvolvimento) ou na própria comercialização de produtos, os agentes estão buscando cada vez mais a adaptação aos novos ambientes organizacionais e institucionais nos quais estão inseridos. No entanto, nesta busca por melhor posição de mercado, tem-se a necessidade de realizar transações que são firmadas por intermédio de contratos.

Quando se elabora um contrato, está implícita a preocupação e o desejo de que as partes envolvidas irão cumprir os acordos firmados. Mas no sistema econômico existem várias atividades produtivas, informação imperfeita, assimetria de informação, incerteza além da racionalidade limitada e oportunismo dos agentes econômicos, que buscam salvaguardar os atributos mais importantes na transação que irão efetivar. Nestes casos, trata-se da possibilidade de detectar a presença de especificidade do ativo, incerteza ou freqüência (denominados de caracteres) nas relações contratuais estabelecidas (contratos).

Esses três caracteres não são visivelmente independentes, apesar das disposições de cláusulas contratuais diferirem bastante de um segmento para o outro. Entretanto, apesar de os contratos se apresentarem em ambientes institucionais e organizacionais diferentes, o intuito é analisar a possível estrutura de dependência que existe entre eles e comparar seus traços principais. Dentre algumas similaridades, considera-se o âmbito que tange à questão dos atributos do custo de transação, que estão intimamente relacionados com as relações contratuais realizadas entres os agentes intra ou extra firma. 
Dessa forma, a AFC, irá proporcionar as propriedades necessárias para detectar essas relações, ou seja, possibilitará enfatizar qual(is) é (são) a(s) principal(is) preocupação dos agentes quando firmam relações contratuais entre si.

Na Tabela 3, observam-se os resultados obtidos através das Equações 1, 2, 3 e 4. Com isso, pode-se constatar que, na primeira coluna, é apresentado o número das dimensões e, nesse caso, foram extraídas apenas duas dimensões, reconstruindo-se os dados apresentados na tabela da freqüência (Tabela 2). Os valores singulares são obtidos pela decomposição do valor singular generalizado através da tabela de freqüências. Os auto-valores são os quadrados dos valores singulares que se somarão à inércia total, mencionada abaixo da Tabela 3 com o valor de 0,75 . A inércia total é definida como o valor da estatística do qui-quadrado $(11,250)$ dividido pelo número total dos casos $(15)$.

Tabela 3 - Auto-valores e Inércia para as dimensões

\begin{tabular}{c|c|c|c|c|c}
\hline \multirow{2}{*}{ Dimensões } & $\begin{array}{c}\text { Valores } \\
\text { Singulares }\end{array}$ & $\begin{array}{c}\text { Auto } \\
\text { Valores }\end{array}$ & $\begin{array}{c}\text { Percentual de } \\
\text { Inércia }\end{array}$ & $\begin{array}{c}\text { Percentual } \\
\text { Acumulado }\end{array}$ & $\begin{array}{c}\text { Valores das estatísticas } \\
\text { qui-quadrado }\left(\chi^{2}\right)\end{array}$ \\
\hline 1 & 0,68423 & 0,46817 & 62,43 & 62,43 & 7,0225425 \\
2 & 0,53088 & 0,28184 & 37,57 & 100,00 & 4,2274575 \\
\hline
\end{tabular}

Total Inércia $=0,7500 \quad X^{2}=11,250 \quad \mathrm{df}=16 \quad \mathrm{p}=0,7938$

Com todas essas informações, pode-se avaliar que as dimensões são computadas de modo que a primeira dimensão extrai a maioria das informações (isto é, tem o auto-valor 0,468) e, a segunda, as demais informações estão na segunda dimensão. Dessa forma, a análise realizada sobre os contratos (objeto) e os atributos da transação (caracteres) mostra que a primeira dimensão extrai $62,42 \%$ da inércia total e a segunda dimensão aumenta a inércia "explicada" em $37,58 \%$, ou seja, estas duas dimensões explicam juntas $100 \%$ do total da inércia. Assim, para uma melhor verificação dessas relações a análise bidimensional é a que melhor se enquadra. A análise de correspondência proporciona um estudo geral da relação objeto e caracteres.

Em se tratando do termo massa, este é usado para denotar as entradas na tabela em dois sentidos de freqüências relativas (isto é, cada entrada 
é dividida pela soma de todas as entradas na tabela). Os resultados da análise da correspondência são ainda medida válida se as entradas na tabela não forem freqüências, mas alguma outra medida da correspondência, tais como a associação, similaridade, confusão etc. Desde que a soma de todas as entradas na tabela de freqüências relativas seja igual a 1, pode-se dizer que a tabela de freqüências relativas mostra como uma unidade da massa é distribuída por meio das linhas e colunas da tabela. Na terminologia da análise da correspondência, a linha e os totais de coluna da tabela de freqüências relativas são chamados a massa da linha e massa da coluna, respectivamente. Neste sentido, quanto mais próximo de 1 estiver a massa, melhor para a análise e para a comparação que se deseja realizar (Tabelas 4 e 5).

Já a qualidade de um ponto é definida como a relação do quadrado da distância do ponto da origem no número escolhido das dimensões sobre a distância quadrado da origem no espaço definido pelo número máximo das dimensões (medido pela estatística do qui-quadrado). Como se pode observar pelas Tabelas 4 e 5 , tanto pontos nas linhas e nas colunas são representados completamente bem na solução bidimensional; a qualidade para todos os pontos é 1 .

Os valores relativos da inércia pertencem à proporção da inércia total “explicada” pelo ponto respectivo. Pode-se notar que um ponto pode bem ser representado em uma solução particular, mas pode não contribuir muito para a inércia total.

A qualidade para cada ponto, devido a cada dimensão, pode ser encontrada nas colunas denominadas de Cosseno ${ }^{2}$ (Cosine $\left.{ }^{2}\right)$. Os valores de Cosseno $^{2}\left(\right.$ Cosine$^{2}$ ) somados através das duas dimensões são iguais ao valor total da qualidade. A contribuição relativa de cada ponto à inércia para cada dimensão (destaca-se que os auto-valores representam as inércias associadas a cada dimensão) está nas Tabelas (4 e 5).

Para confirmar essas informações, o Gráfico 1 retrata o mapa da análise de correspondência. Neste, tem-se a representação simultânea dos atributos da transação (especificidade, incerteza e freqüência) e os contratos de vários segmentos analisados no plano principal $(1,2)$, ou seja, bidimensional, e que por sua vez representa a totalidade da inércia dos pontos nas duas nuvens. 


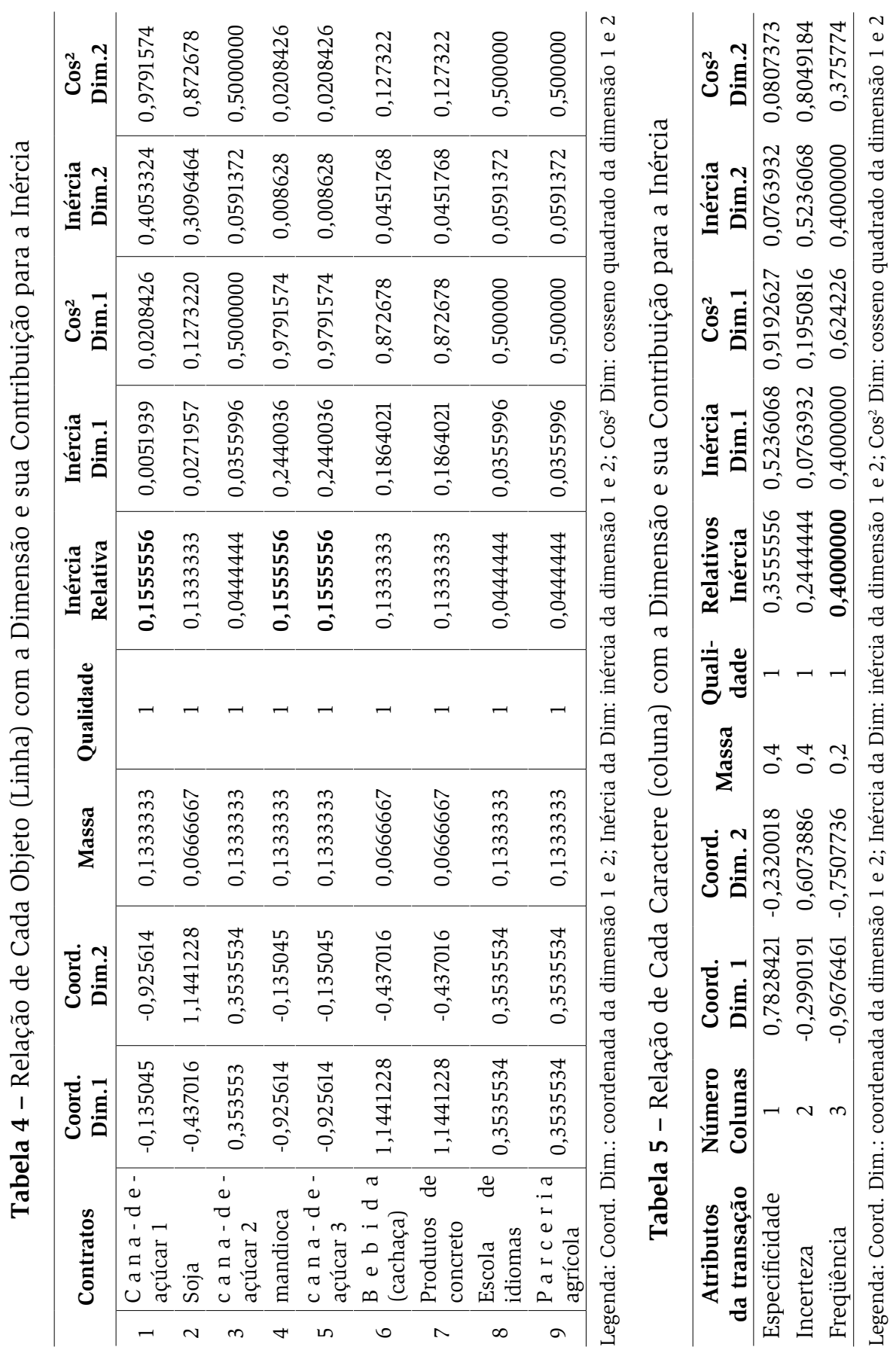


É importante destacar que na criação do mapa perceptual os valores de similaridade (qui-quadrado) oferecem uma medida padronizada da associação, e é por meio destas medidas que se cria uma distância métrica e criam-se dimensões ortogonais sobre as quais as categorias podem ser projetadas, de forma a representar o grau de associação dado pelas distâncias de qui-quadrado (NOGUEIRA, 2003).

Assim, o mapa de análise de correspondência foi elaborado por intermédio da matriz binária 9 X 3, obtida por meio dos valores da Tabela 1. Dessa forma, a exposição dos dados no Gráfico 1 pode ser interpretada pelos valores dos atributos da transação; e cada ponto gera um campo de influência levando-se em consideração a massa. Cada ponto tem seu centro na origem da exposição e, conseqüentemente, cada um é balanceado com o ponto de massa que é proporcionalmente distante da origem; especificidade do ativo e incerteza têm massa de 0,4 e freqüência de 0,4 .

Vale destacar que o mapa da análise de correspondência destaca as relações por meio das proximidades entre os objetos e os caracteres. A origem do eixo representa o centro de gravidade do conjunto de pontos (BOUROCHE; SAPORTA, 1982). Em suma, pode-se afirmar que este mapa mostra por intermédio dos eixos as prováveis pretensões dos agentes quando estabelecem relações contratuais entre si.

A primeira dimensão que representa as abscissas do Gráfico 1 separa os contratos: cana-de-açúcar 3, mandioca, franquia de cachaça e produto de concreto. Todos estes contratos têm cláusulas que tentam resguardar as especificidades de seus ativos, como podem ser observadas nas cláusulas desses contratos. No caso da cana-de-açúcar, que trata de um contrato de compra e venda desta matéria-prima, o produtor se compromete a vender à usina um produto que tenha características qualitativas asseguradas pela concentração total de açúcares (sacarose e açúcares redutores) que sejam recuperados no processo industrial da usina... O contrato com a compra e venda de fécula de mandioca segue, em linhas gerais, para as características qualitativas e quantidade de fécula para cada quilograma de raiz de mandioca. O contrato de franquia resguarda as características de especificidade de marca, cardápio padronizado com pratos e bebidas e treinamento do franqueado e 
sua equipe. O contrato que trata de franquia de materiais de concreto visa resguardar a especificidade de marca como fica explicitado no contrato em sua cláusula 8 ... "todos os produtos serão obrigatoriamente gravados com a marca ' $\mathrm{X}$ ', na forma como se acha registrada, cujo padrão é entregue, neste ato, à franqueada."

Com relação aos contratos franquias de escola de idiomas, parceria agrícola e cana-de-açúcar 2, o modelo não conseguiu de forma clara avaliar o perfil do atributo da transação, mas ao serem analisados pela leitura de suas cláusulas ficou evidente que os contratos visam salvaguardar a especificidade do ativo.

A segunda dimensão que representa o eixo das ordenadas do Gráfico 2 separa os contratos: cana-de-açúcar 1 e soja. Como pode ser observado no contrato de compra e venda de cana-de-açúcar, há uma cláusula que estabelece a entrega do produto em cada safra. Como o contrato foi firmado no estado de São Paulo, o atributo freqüência pode ser importante, face à grande disputa por fornecedores e arrendatários de canade-açúcar pelas usinas paulistas. Já no contrato compra e venda de soja, o atributo incerteza fica patente na cláusula sexta, que trata da entrega no prazo estipulado, delega à compradora poderes para rescindir ou executar, "independentemente da interpelação judicial ou extrajudicial, cumulando pedido de entrega de coisa certa fungível, multa contratual pactuada na cláusula citada e perdas e danos. Se descumpridas a ordem de entrega e restituição, qualquer que seja a causa...” Assim, a segunda dimensão apresenta o característico de na parte positiva da ordenada representar o atributo incerteza e na parte negativa representa a freqüência como pode ser observado no Gráfico 1.

Por sua proximidade com o eixo das abscissas, o atributo especificidade do ativo gera perfis similares de relações contratuais, cujos contratos, que estão mais enquadrados neste eixo, constituem o segmento que provavelmente se baseia neste atributo quando das decisões com relação à elaboração de um contrato. Assim, os contratos (mandioca, cana-de-açúcar 3, franquia de bebida/cachaça, franquia de produtos de concreto) compartilham o mesmo ponto de exposição e têm perfil semelhante no uso da especificidade do ativo, ou seja, sua preocupação está diretamente relacionada com a dificuldade de reemprego ou utilização alternativa de um ativo sem que este tenha perda de valor. 
Os contratos que se enquadram no eixo das ordenadas na parte negativa assumem a característica de valorizar a freqüência como pode ser observado o contrato compra e venda de cana-de-açúcar 1, na utilização desse atributo com maior ênfase no ato da concepção do contrato. Fato que pode ser comprovado na análise da inércia relativa.

Da mesma forma, o contrato 2 (compra e venda de soja) está mais propenso a se preocupar com a incerteza de que os acordos firmados serão mantido até o final da vigência do contrato.

Gráfico 1 - Mapa da Análise Fatorial de Correspondência

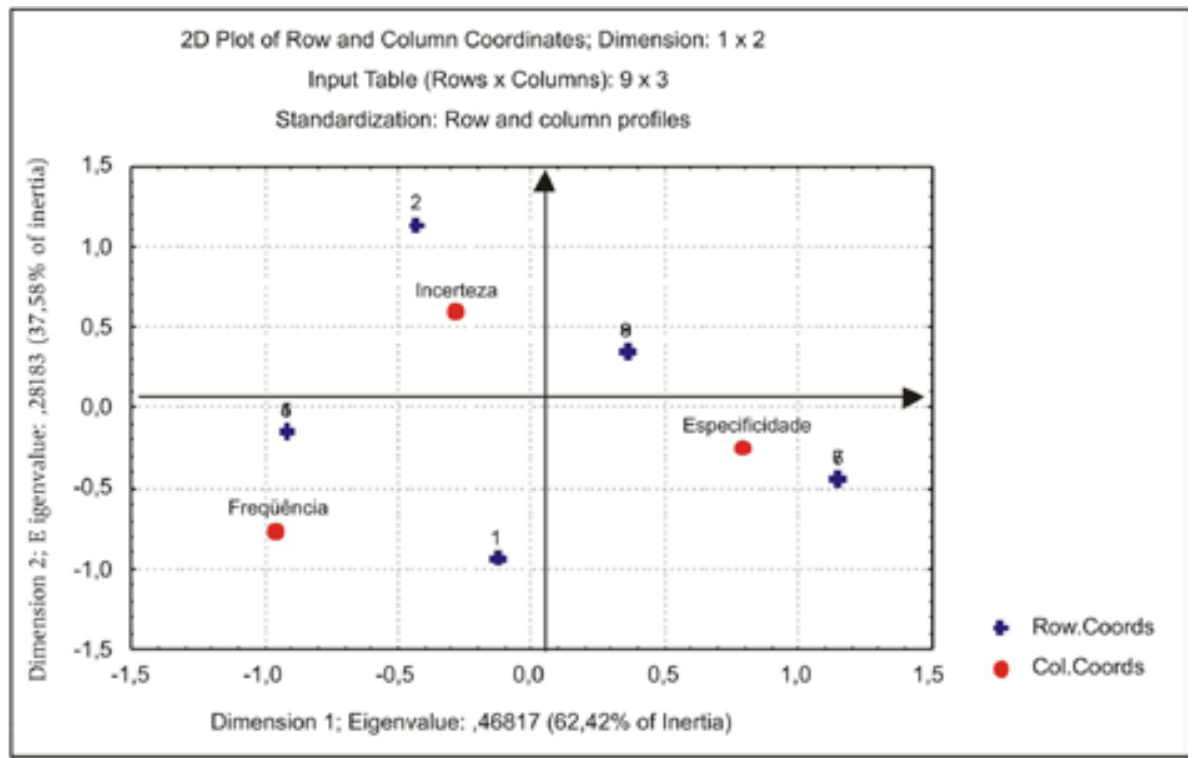

OBS: os números $1,2,3,4,5,6,7,8$ e 9 representam os contratos, conforme apresentado na Tabela 3 , coluna 1 e 2

+ Row. Coords $=$ coordenada linha; $\bullet$ Col. Coords $=$ coordenada coluna.

\section{Considerações finais}

O propósito deste trabalho foi analisar a Economia dos custos de transação para os arranjos contratuais existentes intra e extra firmas, mais especificamente tratar de uma análise fatorial de correspondência aplicada aos contratos. 
O que se deve destacar como importante nesta análise é que o estudo dos custos de transação está diretamente relacionado com o cotidiano vivenciado pelas firmas, sobre o qual são construídos os alicerces das diversas relações existentes entre os agentes, bem como as formas contratuais. As dificuldades de relacionamento entre os agentes podem, em grande parte, ocorrer em razão dos ativos serem específicos, pelas incertezas com relação ao fim dos contratos no prazo estipulado e pela freqüência com que essas relações serão realizadas no futuro.

Dessa forma, elaborou-se um estudo com o instrumental estatístico análise fatorial de correspondência, que possibilitou uma visão mais genérica do grau de relação existente entre os atributos da transação e contratos de segmentos variados.

Assim, os contratos de compra e venda de cana-de-açúcar 2 e 3 , mandioca , franquia de bebida/cachaça, franquia de produtos de concreto, franquia de escola de idiomas e parceria agrícola estão mais ligados à especificidade do ativo, ou seja, sua preocupação reside no fato de haver dificuldade no reemprego ou utilização alternativa de um ativo sem que este tenha perda de valor.

Já os contratos de compra e venda de cana-de-açúcar 1 este direciona maior atenção para a questão da freqüência com que as transações serão realizadas.

O contrato compra e venda de soja está mais propenso à incerteza sobre se os acordos firmados serão mantido até o final da vigência do contrato. Os agentes, devido às incertezas provenientes do mercado, não conseguem criar cláusulas contratuais que associem os resultados futuros do contrato com a realidade futura do mercado, gerando assim insegurança na hora de firmar contratos.

Por fim, devido à complexidade dessa temática, sugere-se, como futuras extensões do presente estudo, que mais pesquisas sejam implementadas para examinar novas contextualizações (sobre as relações entre os atributos da transação - especificidade do ativo, incerteza e freqüência - e os contratos) em outros níveis, já que esta proposta não possibilitou conclusões devido ao número reduzido de contratos disponíveis para a análise. 


\section{Referências bibliográficas}

AZEVEDO, P. F. Integração parcial: instrumento de barganha ou eficiência. In: Associação Nacional de pós-graduação de Economia, Campinas, 1996. Anais ... ANPEC, 1996, p.421-439

BENZÉCRI, J. P. et al. L’analyse des donnés. Tome II. L’analyse des correspondances. Paris: Dunod, 1973. 635 p.

BOUROCHE, J. M.; SAPORTA, G. Análise de dados. Rio de Janeiro: ZAHAR, 1982. $117 \mathrm{p}$.

CARROL, J. D.; GREEN, P. E. An INDSCAL-Based approach to multiple correspondence analysis. Journal of Marketing Research. Chicago. v. 25, n. 2, p. 193-203, May, 1988.

CARROL, J. D.; GREEN, P. E; SCHAFFER, M. C. Interpoint distance comparisons in correspondence analysis. Journal of Marketing Research. Chicago. v. 16, n. 3, p. 271-280, August, 1986.

CARROL, J. D.; GREEN, P. E; SCHAFFER, M. C. Reply to Greenacre's commentary on the Carrol-Green-Schaffer scalling of two-way correspondence analysis solutions. Journal of Marketing Research. Chicago. v. 26, n. 3, p. 366-368. August, 1989.

COASE, R. The nature of the firm. In: WILLIAMSON, O.; WINTER, S. G. (Ed.) In the nature of the firm origins, evolution, and development. New York: Oxford University Press, 1993. 256 p

FARINA, E. M. M. Q. Competitividade e coordenação de sistemas agroindustriais: um ensaio conceitual. Gestão \& Produção, São Carlos, v. 6, n. 3, p. 147-161, dez. 1999.

FARINA, E. M. M. Q.; ZEVEDO, P. F.; SAES, M. S. M. Competitividade: mercado, estado e organizações. São Paulo: Editora Singular, 1997.

GREENACRE, M. J. The Carrol-Green-Schaffer scaling in correspondence analysis: a theoretical and empirical appraisol. Chicago Journal of Marketing Research. v. 26, n. 3, p. 358-365, August, 1989.

GIL, A. C. Técnicas de pesquisas em economia e elaboração de monografias. 3. ed. São Paulo : Atlas, 2000. 217p. 
HOFFMAN, D. L.; FRANKE, G. R. Correspondence analysis: graphical representation of categorical data in marketing research. Chicago. Journal of Marketing Research. Chicago. v. 23, n.3, p. 213-217. August, 1986.

KACIAK, E.; LOUVIERE, J. Multiple correspondence analysis of multiple choice experiment data. Journal of Marketing Research. Chicago. v. 27, n. 4, p. 455-465, November, 1990.

MACEDO JR, R. P. Contratos relacionais e defesa do consumidor. São Paulo: Max Limonad, 1998.

MARDIA, K. V.; KENT, J. T; BIBBY, J. M. Multivariate analysis. London: Academic press. 1989. 518p.

NOGUEIRA, A. C. L. Custos de transação e arranjos institucionais alternativos: uma análise da avicultura de corte no Estado de São Paulo. 153 f. São Paulo, 2003. Universidade de São Paulo, Faculdade de Economia, Administração e Contabilidade - USP.

NORTH, D. Custos de transação, instituições e desempenho econômico. Rio de Janeiro: Instituto Liberal, 1994. 38 p.

SILVA, E.; VERTINELLI, M. A. Avaliação em massa de terrenos em Blumenau (Santa Catarina - Brasil) usando análises fatorial de correspondência e regressão múltipla. Santa Catarina: Universidade Federal de Santa Catarina, n. 09/97. Outubro 1997.

SZTAJN, R.; ZYLBERSZTAJN, D.; AZEVEDO, P. F. Economia dos contratos. In. SZTAJN, R.; ZYLBERSZTAJN, D. (org.). Direito e Economia: Análise econômica do Direito e das Organizações. Rio de Janeiro: Elsevier. 2005. 102 - 137.

VERDINELLI. M. A. Análise inercial em ecologia. 1980. 162 f. Tese (Doutorado em Ciências Biológicas) - USP, São Paulo

WILLIAMSON, O. Transaction-cost economics: the governance of contractual relations. Journal of Law and Economics, Chicago, v. 22, n. 2, p. 233-261, Oct. 1979.

The modern corporation: origins, evolution, and attributes. Journal of Economic Literature, Stanford, v. 19, n. 4, p. 1537-1568, Dec. 1981. 
ZYLBERSZTAJN, D. A estrutura de governança e coordenação do agribusiness: uma aplicação da nova economia das instituições. 1995. 238 f. Tese (Livre-Docência) - Faculdade de Economia, Administração e Contabilidade, Universidade de São Paulo, São Paulo.

Papel dos contratos na coordenação agro-industrial: um olhar além dos mercados. Revista de Economia e Sociologia Rural, Brasília, v. 43, n. 3, p. 385-420, jul./set. 2005.

ZYLBERSZTAJN, D.; NEVES, M. F. (Org.) Economia e gestão de negócios agroalimentares. São Paulo: Pioneira, 2000.

WILLIAMSON, O. The modern corporation: origins, evolution, and attributes. Journal of Economic Literature, Stanford, v. 19, n. 4, p. 1537-1568, Dec. 1981. 